\title{
Race and Sexual Identity Differences in PrEP Continuum Outcomes Among Latino Men in a Large Chicago Area Healthcare Network
}

\author{
Casey D. Xavier Hall ${ }^{1,2} \odot$ Brian A. Feinstein ${ }^{3}$. Laura Rusie ${ }^{4} \cdot$ Gregory Phillips II $^{1,2} \cdot$ Lauren B. Beach $^{1,2}$
}

Accepted: 22 November 2021 / Published online: 7 January 2022

(c) The Author(s), under exclusive licence to Springer Science+Business Media, LLC, part of Springer Nature 2021

\begin{abstract}
U.S. HIV incidence is threefold higher among Latino individuals than non-Latino Whites. Pre-exposure prophylaxis (PrEP) uptake remains low among Latino men. Most HIV studies view Latino communities as a monolithic group, ignoring racial and sexual diversity. This analysis examines PrEP-related outcomes including eligibility, first prescription, and second prescription across race and sexual identity in a sample of Latino cisgender men $(n=8271)$ who sought services from a healthcare network in Chicago in 2012-2019. Logistic regression was used to calculate adjusted odds ratios. Latino-only participants had lower odds of PrEP eligibility and first prescription compared to White-Latino participants. No other significant differences by race were detected. While bisexual participants had equivalent odds of PrEP eligibility, they had lower odds of first PrEP prescription compared to gay participants. Heterosexual participants also had lower odds of PrEP eligibility and initiation. Future research should address unique factors shaping PrEP-related outcomes among diverse Latino populations.
\end{abstract}

Keywords Disparity $\cdot$ HIV $\cdot$ PrEP $\cdot$ Race $\cdot$ Sexual identity

\section{Resumen}

La incidencia del VIH en los EEUU és 3 veces mayor entre las personas latinos que entre los blancos no latinos. La iniciación de la profilaxis previa a la exposición (PrEP) sigue siendo baja entre los hombres latinos. La mayoría de los estudios sobre el VIH ven a las comunidades latinos como un grupo monolítico, ignorando la diversidad racial y sexual. Este análisis examina los resultados relacionados con la PrEP, incluida la elegibilidad, la primera prescripción y la segunda prescripción según la raza y la identidad sexual en una muestra de hombres latinos cisgénero $(n=8.271)$ que buscaron servicios de una gran red de servicios de salud en Chicago 2012-2019. Se utilizó la regresión logística para calcular las razones de momios ajustadas. Los participantes que solo eran latinos tenían menores probabilidades de ser elegibles para PrEP y de recibir la primera prescripción en comparación con los participantes de blancos-latinos. No se detectaron otras diferencias significativas por raza. Si bien los participantes bisexuales tenían probabilidades equivalentes de ser elegibles para PrEP, tenían probabilidades más bajas de recibir la primera prescripción de PrEP en comparación con los participantes homosexuales. Los participantes heterosexuales también tenían menores probabilidades de ser elegibles y de iniciarse en la PrEP. Las investigaciones futuras deben abordar los factores únicos que dan forma a los resultados relacionados con la PrEP entre las diversas poblaciones latinos.

Casey D. Xavier Hall

casey.xavier.hall@northwestern.edu

1 Department of Medical Social Sciences, Northwestern University Feinberg School of Medicine, 625 N Michigan Ave, Suite 1400, Chicago, IL 60611, USA

2 Northwestern University Institute for Sexual and Gender Minority Health and Wellbeing, Chicago, IL, USA

3 Department of Psychology, Rosalind Franklin University of Medicine and Science, North Chicago, IL, USA

4 Howard Brown Health, Chicago, IL, USA

\section{Introduction}

While the number of new HIV diagnoses in the US continues to decrease over time [1], men who have sex with men $\left(\mathrm{MSM}^{1}\right)$ still make up the largest proportion of new

\footnotetext{
${ }^{1}$ Here the term MSM refers to individuals who have sex with men regardless of their sexual identity, which includes heterosexual men who have sex with men. We use more specific identity labels such as gay, bisexual, or men who have sex with men and women (MSMW) where appropriate.
} 
diagnoses. For example, in 2018, MSM accounted for $69 \%$ of all new HIV diagnoses in the US [2]. In addition, Black and Latino MSM are disproportionately affected by HIV relative to White MSM. In 2018, Black and Latino MSM accounted for $37 \%$ and $30 \%$, respectively, of all new HIV diagnoses among MSM in the US, while White MSM made up $27 \%$ [3, 4]. Although advances in biomedical HIV prevention have led to novel strategies for preventing HIV, such as pre-exposure prophylaxis (PrEP), emerging evidence suggests that PrEP may be reaching some groups of men (e.g., White, gay) more than others (e.g., Black and Latino, bisexual or heterosexual). Furthermore, in public health research, Latin $\mathrm{x}^{2}$ people are typically treated as a homogenous ethnic group (i.e., race is ignored), and MSM are also treated as a homogenous group in contrast to heterosexual men with limited attention to sexual identities within the MSM category (e.g., gay vs. bisexual). Additionally, research on PrEP use among heterosexual men in the U.S. remains relatively scant [5], further limiting our understandings of sexual identity differences in PrEP use. As a result, little is known about potential subgroup differences in PrEP use among Latino men. To address this gap in the literature, we examined racial and sexual identity differences in PrEP eligibility and use (including first prescription and second prescription) among Latino men using electronic medical records from a Chicago area healthcare network.

\section{Racial Differences in PrEP Eligibility and Use Among Latino Men}

Despite the promise of PrEP for HIV prevention, uptake remains low in the US [6-9], especially for Black and Latino MSM. For example, it has been estimated that only $10 \%$ of those who might benefit from PrEP have initiated it [10], and that only $2 \%$ of Black and Latinx individuals who could benefit from it filled a prescription in 2015 and 2016 [11]. Of note, these studies treated Latino as a homogenous ethnic group, and emerging evidence suggests that there may be racial differences in HIV and related outcomes among Latino MSM. Specifically, one study found that the prevalence of HIV among Black-Latino young MSM neared that

\footnotetext{
${ }^{2}$ Here we choose the gender neutral term Latinx over alternatives such as the masculine Latino as a gender-expansive term that encompasses gender-specific terms such as Latino and Latina [59, 60]. We use the term Latinx when referring to gender diverse populations and Latino when referring to men. We use the terms Latinx and Latino to encompass the ethnic category of Hispanic as well as other people with origins in Latin America. This is overlapping, but different from definitions of Hispanic that often only include origins in Spanishspeaking Latin America. For example, Latinx/Latino include people with origins in Brazil, which makes up more than a third of the population of South America and where the majority of the population speak Portuguese.
}

of Black non-Latino young MSM (28\% and 31\%, respectively), while the prevalence of HIV among White-Latino MSM was similar to that of White non-Latino MSM (5\% and $4 \%$, respectively) [12]. These disparities may have been related to differences in sexual partnering, particularly since there was evidence of racial homophily between Latino and non-Latino MSM (e.g. being more likely to partner with someone of a similar racial and/or ethnic background) [12], but it has also been suggested that racial disparities in the health of Latinx individuals is likely the result of structural inequities (e.g., compared to White-Latinx populations, Black-Latinx populations are more likely to experience unemployment and poverty) [13]. In addition, another study found that, among people living with HIV, Black-Latinx individuals had an increased risk of mortality compared to White-Latinx individuals, even after controlling for individual and neighborhood factors [14]. Together, these findings highlight the importance of attending to both race and ethnicity in order to understand the health of Latino men. To our knowledge, no prior studies have investigated racial differences in PrEP eligibility and use among Latino men.

Ignoring racial variability among Latinx people is a common practice in public health research including studies of HIV [11, 13-15]. However, this practice may obscure important subgroup differences among Latinx people of different races. It is common for researchers to use the two-question format from the U.S. census [16, 17], where participants are asked one question about their race (without a Latinx option) and a second question about whether they are of Hispanic ethnicity $[16,17]$. Typically, the census and health researchers combine the responses of these two questions into a single variable of "race/ethnicity" where individuals who are Hispanic are treated as a single category. ${ }^{3}$ Researchers who focus on issues of race and ethnicity often view these constructs as overlapping and have differing views on the precise definitions of each $[17,18]$. There is a substantial proportion of individuals with Latinx ethnicity who identify as Latinx-only, meaning that they identify exclusively as Latinx and do not identify with Latinx in combination with another racial category [19]; however, individuals also identify as Latinx in combination with other racial categories such as Latinx and White or Latinx and Black. This highlights the complexity of considering Latinx ethnicity and racial identity within the context of the U.S. In this way, using the two-question approach to consolidate all Latinx individuals into a single category does not align with the lived experiences of many Latinx people.

\footnotetext{
3 The U.S. Census Bureau conceptualizes the term "Hispanic" to encompass "Latinx" [51].
} 


\section{Sexual Identity Differences in HIV and Related Outcomes Among Latino Men}

In addition to treating Latino men as a homogenous ethnic group, research on HIV has historically treated MSM as a homogenous group with limited attention to potential differences based on sexual identity, especially between gay and bisexual men [20]. Morever, there is a paucity of research addressing PrEP use among heterosexual men in the U.S. [5].

While there has been some attention to behaviorally bisexual men (i.e., men who have sex with men and women [MSMW]), the category MSMW is not inclusive of all bisexual men and may include heterosexual men [21]. For example, among sexually active men ages $24-32$, only $45 \%$ of those who described themselves as bisexual or mostly heterosexual (but somewhat attracted to their own sex) reported having had sex with both male and female partners in their lifetime [20]. Moreover, behavioral categories such as MSM and MSMW have been criticized for ignoring the context in which sexual behavior occurs (e.g., social and cultural norms) and for obscuring important differences based on identity $[22,23]$.

The available evidence based on sexual identity (as opposed to sexual behavior) suggests gay and bisexual men are both at increased risk for HIV and other sexually transmitted infections (STI). For example, in a nationally representative sample, $17.4 \%$ of gay men and $7.7 \%$ of bisexual men were HIV-positive compared to $0.3 \%$ of heterosexual men who had never had sex with men [24]. Furthermore, in another nationally representative sample, $18.2 \%$ of gay men and $17.7 \%$ of bisexual men reported being diagnosed with an STI (genital warts, herpes, or syphilis) in their lifetime compared to $5.3 \%$ of heterosexual men [25]. Together, these findings suggest that gay and bisexual men are both at increased risk for HIV/STIs, although gay men experience the greatest burden of HIV infection.

There is also evidence that there may be important differences between gay and bisexual men with respect to sexual risk and preventive behavior. For example, compared to gay men, bisexual men are more likely to engage in insertive condomless anal sex (CAS) with casual partners and they are more likely to report substance use before sex $[26,27]$. Recent studies have also found that bisexual men are less likely to get tested for HIV/STIs than are gay men, and that they get tested less frequently [25, 27, 28]. In addition, while PrEP uptake remains low among MSM in general [29, 30], bisexual men are less likely to use PrEP than are gay men [27, 31]. Together, these findings highlight the importance of attending to sexual identity in studies of HIV and related outcomes among MSM. However, our understanding of sexual identity differences in PrEP use remains limited. Specifically, we are not aware of any studies that have examined sexual identity differences in PrEP eligibility based on CDC criteria [32]. This is important, because many US-based studies focus on MSM as a homogenous category or gay men exclusively and very little research examines PrEP use in heterosexual men in the context of the US. While heterosexual men have lower risk for HIV transmission relative to gay and bisexual men, there are still heterosexual men at risk of HIV transmission [24] and PrEP is an effective strategy for prevention among heterosexual men [33]. Very little research about heterosexual men and PrEP use in the U.S. exists outside of studies that focus on intravenous drug use and heterosexual men who have sex with men [5]. Despite this, PrEP is a potentially beneficial intervention for a range of sexual identities including bisexual and heterosexual men.

Additionally, prior studies have focused on self-report of PrEP use rather than more objective data such as PrEP prescription in electronic medical records (EMR) and often without attention to continued healthcare engagement for PrEP such as monitoring additional prescriptions after the first prescription. Furthermore, none of the aforementioned studies on sexual identity and PrEP focused specifically on Latino men or variations within this group by race and sexual identity. Scholars have called for greater attention to differences between self-identified gay and bisexual men at the intersections of race and ethnicity [19].

\section{The Current Study}

In sum, while we know that Latino and non-Latino Black MSM are at higher risk for HIV transmission and have low PrEP uptake compared to white MSM, less is known about racial differences within Latino men (e.g. comparing Black Latino, Latino-only, or White Latino), Moreover, literature has emphasized sexual behavior categories such as MSM or MSMW rather than examining differences by sexual identity among men (e.g. comparing gay, bisexual, and heterosexual). This limits our understanding of how PrEP use varies by sexual identity, particularly among bisexual and heterosexual men. Many studies are experiments or observational surveys, which may have biases in regard to the selection of participants. In response to these limitations in the literature, the current study seeks to examine racial and sexual identity differences in PrEP eligibility and use (including first prescription and second prescription) among a sample of cisgender Latino men. By conducting retrospective analyses using EMR from a multisite federally qualified health center (FQHC) in Chicago area we hope to more closely approximate patient behaviors outside of an experimental setting and limit response biases that are present in survey research. 


\section{Method}

\section{Participants and Procedures}

The data set used in these analyses was pulled from the EMR of a Chicago area FQHC (Howard Brown Health), which includes multiple locations throughout Cook County, Illinois. The research protocol was approved by the Institutional Review Boards of Howard Brown Health and Northwestern University.

Data were pulled from existing EMR data from all possible locations within the healthcare network using the following inclusion criteria for these analyses: (1) patients identified as cisgender men, (2) patients identified as Latino, (3) patient records were from after 2012, since PrEP was introduced to the public at this time, (4) patients were HIVnegative at the time of their first recorded visit within the dataset. As this analysis focuses on sexual identity, participants did not have to report male sexual partners to be included in this analysis. Data were pulled and anonymized by approved healthcare network staff before being analyzed. Demographic characteristics and PrEP eligibility were assessed at the first recorded visit. Longitudinal prescription data from the time of the first visit until the time of analysis in fall 2019 were pulled and linked to initial visit records for analysis. Given that the first detected case of COVID-19 in Chicago was in January of 2020 and full stay-at-home orders were issued by March 20, 2020 [34], data was not pulled from the 2020 year due to the impact of the pandemic to isolate medical records that represented pre-pandemic patterns.

This study was conducted using the "Bi Us, For Us" model, meaning this analysis was part of a broader project conceptualized collaboratively by bisexual community advocacy organizations, a healthcare network, and academic researchers [35]. The aims and approach of this analysis were designed and implemented in partnership with members of the Howard Brown Health Bisexual Health Working Group and the Chicago Bisexual Health Task Force. The authors include academic researchers, bisexual community organizers, people who identifiy as bisexual, and a member of the healthcare network. This analysis arose out of discussion between researchers, healthcare providers, and bisexual community members about healthcare needs in bisexual communities including discussion of how healthcare experiences are impacted by the intersections of racial and sexual identities. This approach ensured that the analysis and the outputs of the analysis aligned with bisexual community needs. This included presentations delivered directly to bisexual community members and advocates allowing for feedback on the results. Dissemination also involved presentations to healthcare network leadership and to both Chicago and national bisexual communities.

\section{Sample Characteristics}

All participants self-identified as Latino $(n=8271)$. The two largest racial categories within the analytic sample were Latino-only ${ }^{4}(47.8 \%)$ and White $(42.7 \%)$ followed by Black (3.7\%), Asian or Pacific Islander (2.3\%), Multiracial (1.8\%), and Native American/Indigenous (1.6\%). The largest sexual identity group was gay $(61.4 \%)$ followed by heterosexual/ straight $(30.7 \%)$ and bisexual $(7.9 \%)$. The mean age was approximately 35 years and the mean initial appointment year was about 2015, indicating that on average the first year on record was in 2015. A minority of participants preferred Spanish language at appointments (8.3\%). The majority of participants attended North Chicago clinics $(91.0 \%)$ and were in the lowest income bracket (57\%). For more detail, see Table 1.

\section{Measures}

\section{PrEP Eligible (screening)}

PrEP eligibility was assessed by clinical staff utilizing a standardized EMR form based on CDC criteria, independent clinical judgement (meaning that the provider made a judgement about HIV risk based on patient history with CDC criteria in mind), or a combination of the two. As this dataset is from EMR, assessments reflect actual clinical practices, which often allow for clinical judgement in addition to standard screening procedures. For this analysis eligibility was assessed at the first recorded visit in the dataset. Using indicators based on recommendations from the Centers for Disease Control and Prevention, a participant was coded as PrEP eligible [1] or PrEP ineligible (0) [32]. To be considered PrEP eligible, participants needed to meet at least one of the following criteria: having a partner living with HIV, being diagnosed with an STI in the preceding 12 months (including a history of rectal STIs in the preceding 12 months or a positive STI test at the time of visit), having multiple sexual partners, having condomless sex (anal or vaginal), sharing needles for injection drug use, or participating in sex work. Frequencies for each criterion are indicated in the results. Participants could have more than one criterion. Participants who did not have a CDC-based criterion indicated were labeled "reason unknown."

\section{First PrEP Prescription}

First PrEP prescription was calculated based on longitudinal prescription data that was linked to the initial visit through

\footnotetext{
${ }^{4}$ Latino-only refers to participants who only indicated Latino and no other racial identity.
} 
Table 1 Descriptive statistics in sample of Latino men $(\mathrm{n}=8271)$

\begin{tabular}{|c|c|}
\hline Variable & $\mathrm{N}(\%)$ \\
\hline \multicolumn{2}{|l|}{ Race } \\
\hline Latino only & $3953(47.8 \%)$ \\
\hline Black & $305(3.7 \%)$ \\
\hline Native American/Indigenous & $136(1.6 \%)$ \\
\hline White & $3587(42.7 \%)$ \\
\hline Asian or Pacific Islander & $193(2.3 \%)$ \\
\hline Multiracial & $152(1.8 \%)$ \\
\hline \multicolumn{2}{|l|}{ Sexual identity } \\
\hline Bisexual & $651(7.9 \%)$ \\
\hline Gay & $5081(61.4 \%)$ \\
\hline Heterosexual/straight & $2,539(30.7 \%)$ \\
\hline \multicolumn{2}{|l|}{ Spanish language preferred } \\
\hline Yes & $685(8.3 \%)$ \\
\hline No & $7586(91.7 \%)$ \\
\hline \multicolumn{2}{|l|}{ Primary Location } \\
\hline North Chicago clinics & $7523(91.0 \%)$ \\
\hline Other location & $748(9.0 \%)$ \\
\hline \multicolumn{2}{|l|}{ Monthly Income } \\
\hline$\$ 823$ or less & $4713(57.0 \%)$ \\
\hline$\$ 824$ to $\$ 3343$ & $2670(31.0 \%)$ \\
\hline$\$ 3344+$ & $988(12.0 \%)$ \\
\hline \multicolumn{2}{|l|}{ PrEP eligible at appointment } \\
\hline Yes & $4335(52.4 \%)$ \\
\hline No & $3936(47.6 \%)$ \\
\hline \multicolumn{2}{|l|}{ First prescription within one year } \\
\hline Yes & $1373(23.6 \%)$ \\
\hline No & $6898(76.4 \%)$ \\
\hline \multicolumn{2}{|c|}{ Second prescription without pill outage } \\
\hline Yes & $1126(14.0 \%)$ \\
\hline \multirow[t]{2}{*}{ No } & $7,145(86.0 \%)$ \\
\hline & Mean (SD) \\
\hline Age & $35.1(10.5)$ \\
\hline Year of appointment & $2015.7(2.4)$ \\
\hline
\end{tabular}

a participant ID number. The time to first prescription was calculated by subtracting the date of the first prescription on record from the initial visit data. Participants were coded as having received a first prescription if they: (1) were identified as PrEP eligible and (2) were given at least one prescription in the first year after screening as eligible. The second criterion was created based on the average time and ranges in time to PrEP initiation in existing literature [36, 37]. A sensitivity analysis was conducted changing the one-year threshold to 6-month and 3-month thresholds.

\section{Second PrEP Prescription}

Second PrEP prescription was calculated using multiple variables from the longitudinal prescription data including PrEP supply in number of pills as well as the dates of prescription fills. The number of days between prescription receipt dates was calculated using the dates from the first and second prescription. If participants received their second prescription within a sufficient number of days to avoid a pill outage (i.e., the number of pills was greater than the number of days) then they were coded as having a second PrEP prescription. Participants were coded as not having a second PrEP prescription without a lapse in pill supply if: (1) they did not have a second prescription on record or (2) if the record on file was not within the correct number of days to avoid a pill outage, because this would indicate that the participant had a lapse in pill supply leading to an outage prior to their second prescription.

\section{Race and Ethnicity}

All participants included in the current analyses self-identified as Hispanic/Latino in their intake form. As described in the introduction we are using the term Latino because the sample includes only cisgender men. In order to examine differences by race, participants were classified by the racial classification that they provided on standardized registration paperwork at intake. These included White, Black, Asian/ Pacific-Islander, Multi-racial, and Native American/Indigenous. A participant was marked as Latino-only if: (1) they did not indicate a racial classification, declined to indicate a racial classification, or had a racial classification that was designated as "unspecified;" and (2) they indicated Latino ethnicity.

\section{Sexual Identity}

Sexual identity data collected on standardized registration paperwork at intake. Three sexual identity categories were included in this analysis: "gay," "straight/heterosexual" and "bisexual" based on patient self-identification only. Sexual behavior was not taken into account in these categorizations. In this study, the identity labels do not represent combined categories of other identities (e.g. queer, pansexual, etc.). Although "other" sexual identities were also collected in the standardized intake form these identities were not included due to smaller sample sizes in these other categories.

\section{Demographics and Other Variables}

Other variables included the year of initial visit and participant age at initial visit. Data was also pulled from medical records indicating if a participant preferred having a Spanish interpreter at the initial appointment. This variable was included, because research suggests that speaking or preferring Spanish language can impact patient experiences and awareness of PrEP [38]. There were not sufficient numbers of participants 
Table 2 Differences in recorded eligibility criteria among a sample of Latino cisgender men, odds ratios by sexual identity

\begin{tabular}{lllll}
\hline Eligibility criteria & $\begin{array}{l}\text { Total } \\
\mathrm{n}(\%)\end{array}$ & $\begin{array}{l}\text { Gay } \\
\text { OR }(95 \% \mathrm{CI})\end{array}$ & $\begin{array}{l}\text { Bisexual } \\
\text { OR }(95 \% \mathrm{CI})\end{array}$ & $\begin{array}{l}\text { Heterosexual } \\
\text { OR }(95 \% \mathrm{CI})\end{array}$ \\
\hline STI ( past 12 months) & $1399(32.3 \%)$ & Ref & $0.87(0.69,1.10)$ & $0.99(0.84,1.16)$ \\
Rectal STI & $477(11.0 \%)$ & Ref & $0.82(0.59,1.14)$ & $0.12(0.07,0.20)^{* * *}$ \\
Chlamydia positive at visit & $701(16.2 \%)$ & Ref & $0.94(0.70,1.28)$ & $2.26(1.88,2.71)^{* * *}$ \\
Partner living with HIV & $319(7.4 \%)$ & Ref & $0.57(0.37,0.89)^{*}$ & $0.10(0.06,0.20)^{* * *}$ \\
Multiple partners & $2450(56.5 \%)$ & Ref & $1.44(1.16,1.78)^{* * *}$ & $2.79(2.36,3.29)^{* * *}$ \\
Condomless anal sex & $29(0.7 \%)$ & Ref & $0.57(0.13,2.42)$ & - \\
Condomless vaginal sex & $0(0 \%)$ & - & - & - \\
Exchange sex & $33(0.8 \%)$ & Ref & $2.90(1.21,6.94)^{*}$ & $1.29(0.54,3.08)$ \\
Shared injection & $6(0.1 \%)$ & - & - & - \\
Reason unknown & $938(21.6 \%)$ & Ref & $0.71(0.55,0.91)^{* *}$ & $0.08(0.05,0.11)^{* * *}$ \\
\hline$* \mathrm{P}<0.05$ & & & & \\
$* * \mathrm{P}<0.01$ & & & & \\
$* * * \mathrm{P}<0.001$ & & & &
\end{tabular}

requesting Portuguese interpreters or interpreters for other commonly spoken languages in Latin America to allow for controlling for other languages. The primary service location for the initial appointment was collected as a specific clinic within the network that was then categorized by region in the city ("North" or "Other location"). The "other location" category was created by combining Western, Southern and mobile outreach locations due to smaller numbers in these categories. Monthly income data was categorized into three categories based on 2019 federal income tax brackets for single persons: $\$ 823$ or less, between $\$ 824$ and $\$ 3343$, and $\$ 3344$ or above. Sex of partners are also indicated in the results as "exclusively female," "exclusively male," and "both male and female."

\section{Analysis}

All analyses were conducted in SAS version 9.4. Descriptive analyses were conducted to examine distributions of data, examine assumptions of statistical tests and models, and examine missingness. Bivariate analyses were used to examine the relationships between variables of interest and the PrEP cascade outcomes. A series of logistic regressions were conducted to examine each of the outcomes. The samples from these regressions were nested, because the first regression includes all participants to examine eligibility, the second includes only eligible participants to examine first prescription and last included only participants who had a first prescription to examine second prescription.

\section{Results}

Of the full sample $(n=8271), 52.4 \%$ were PrEP eligible. Of those who were eligible (4335), 31.7\% had a first prescription. Of those who had a first prescription $(n=1373), 82.0 \%$ received a second prescription. The sex of sexual partners varied by sexual identity $\left(\mathrm{X}^{2}=4898.11\right.$ (4), $\left.\mathrm{p}<0.001\right)$. Among heterosexual participants $84.9 \%$ reported exclusively female partners, $10.7 \%$ reported both male and female partners and $4.4 \%$ reported exclusively male partners. Among bisexual participants, $6.3 \%$ reported exclusively female partners, $49.0 \%$ reported both male and female partners, and $44.7 \%$ reported exclusively male partners. Among gay participants $95.7 \%$ reported exclusively male partners, $3.7 \%$ reported male and female partners, and $0.5 \%$ reported exclusively female partners.

\section{Reasons for Eligibility}

Reasons for eligibility are presented in Table 2. The most frequent reported reason was having multiple partners (56.5\%) followed by having an STI in the past 12 months $(32.3 \%)$ and an unknown reason $(21.6 \%)$. The "reason unknown" category represents patients who were deemed eligible by a provider without an explicitly recorded reason. This may represent cases that were deemed eligible based on individual provider clinical judgement or instances where a provider neglected to record a reason for eligibility. Notably, no participants were indicated as eligible due to vaginal sex and very few were indicated eligible due to condomless anal sex $(0.7 \%)$, exchange sex $(0.8 \%)$ or shared injection $(0.1 \%)$.

When conducting unadjusted logistic regressions bivariate differences by sexual identity were observed 6 of the 9 reasons for eligibility that were reported. Odds ratios (OR) and confidence intervals (CI) are presented in Table 2). Heterosexual participants had lower odds of having rectal STI (OR $=0.12,95 \%$ CI 0.07, 0.20), having partner living with HIV $(\mathrm{OR}=0.10,95 \% \mathrm{CI} 0.06,0.20)$, and having an unknown reason $(\mathrm{OR}=0.08,95 \% \mathrm{CI} 0.05,0.11)$ as indicated criteria relative to gay participants. Meanwhile, heterosexual 
Table 3 Differences in recorded eligibility among a sample of Latinx cisgender men, odds ratios for criteria by racial identity

\begin{tabular}{|c|c|c|c|c|c|c|}
\hline \multirow[t]{2}{*}{ Eligibility criteria } & \multirow{2}{*}{ White } & \multirow{2}{*}{$\begin{array}{l}\text { Black } \\
\text { OR }(95 \% \mathrm{CI})\end{array}$} & \multirow{2}{*}{$\begin{array}{l}\text { Asian or Pacific } \\
\text { Islander } \\
\text { OR }(95 \% \mathrm{CI})\end{array}$} & \multirow{2}{*}{$\begin{array}{l}\text { American Indian/Indig- } \\
\text { enous } \\
\text { OR }(95 \% \mathrm{CI})\end{array}$} & \multirow{2}{*}{$\begin{array}{l}\text { Latino Only } \\
\text { OR (95\% CI) }\end{array}$} & \multirow{2}{*}{$\begin{array}{l}\text { Multiracial } \\
\text { OR }(95 \% \mathrm{CI})\end{array}$} \\
\hline & & & & & & \\
\hline STI ( past 12 months) & Ref & $0.87(0.61,1.23)$ & $1.14(0.75,1.72)$ & $1.19(0.75,1.89)$ & $1.15(1.01,1.32)^{*}$ & $0.68(0.43,1.09)$ \\
\hline Rectal STI & Ref & $0.58(0.32,1.06)$ & $1.05(0.58,1.90)$ & $1.65(0.93,2.94)$ & $0.85(0.70,1.04)$ & $0.73(0.36,1.46)$ \\
\hline $\begin{array}{l}\text { Chlamydia positive at } \\
\text { visit }\end{array}$ & Ref & $0.78(0.49,1.25)$ & $0.69(0.37,1.27)$ & $1.39(0.81,2.41)$ & $1.16(0.98,1.37)$ & $0.59(0.30,1.14)$ \\
\hline Partner living with HIV & Ref & $0.93(0.52,1.67)$ & $0.32(0.10,1.02)$ & $1.17(0.56,2.47)$ & $0.74(0.58,0.94)$ & $1.07(0.53,2.15)$ \\
\hline Multiple partners & Ref & $0.95(0.64,1.41)$ & $0.92(0.59,1.43)$ & $0.87(0.63,1.19)$ & $1.18(1.04,1.34)^{*}$ & $1.03(0.69,1.54)$ \\
\hline Condomless anal sex & Ref & $1.14(0.54,2.40)$ & $1.40(0.18,10.71)$ & - & $1.14(0.54,2.40)$ & - \\
\hline Condomless vaginal sex & - & - & - & - & - & - \\
\hline Exchange sex & Ref & $1.55(0.35,6.81)$ & - & $1.56(0.21,11.91)$ & $0.93(0.55,2.93)$ & $1.27(0.17,9.65)$ \\
\hline Shared injection & Ref & - & - & - & - & - \\
\hline Reason unknown & Ref & $0.97(0.67,1.40)$ & $1.05(0.67,1.65)$ & $1.04(0.63,1.73)$ & $0.64(0.66,0.75)^{* * *}$ & $1.35(0.87,2.08)$ \\
\hline
\end{tabular}

$* \mathrm{P}<0.05$

$* * \mathrm{P}<0.01$

$* * * \mathrm{P}<0.001$

men had higher odds of having chlamydia $(\mathrm{OR}=2.26,95 \%$ CI $1.88,2.71)$, or multiple partners (OR $=2.7995 \% \mathrm{CI}$ $2.36,3.29)$ as indicated criteria relative to gay participants. Bisexual participants had lower odds of having a partner living with $\mathrm{HIV}$ as an indicated criterion $(\mathrm{OR}=0.57,95 \%$ CI $0.37,0.89)$ and having an unknown reason $(\mathrm{OR}=0.71$, $95 \%$ CI $0.55,0.91)$ relative to gay men. Bisexual men had higher odds of having multiple partners ( $O R=1.44,95 \%$ CI $1.16,1.78)$ and exchange sex $(2.9095 \%$ CI $1.21,6.94)$ as indicated criteria.

Table 3 shows ORs for eligibility criteria by racial identity. Only three criteria had differences by race. Latino-only men had higher odds of STI in the past year $(\mathrm{OR}=1.15$, $95 \%$ CI 1.01, 1.32) and having multiple partners $(\mathrm{OR}=1.18$, 95\% CI 1.04, 1.34) indicated compared to white participants. Latino-only men had lower odds of not having known reason $(\mathrm{OR}=0.64,95 \%$ CI 0.66, 0.75).

\section{Regressions}

\section{Bivariate Associations}

In the unadjusted logistic regression models, race was significantly associated with eligibility and first prescription. Latino-only participants had lower odds of being eligible $(\mathrm{OR}=0.60,95 \% \mathrm{CI} 0.55,0.66)$ and lower odds of having a first prescription $(\mathrm{OR}=0.58,95 \%$ CI $0.50,0.66)$ compared to White participants. Multi-racial participants had higher odds of being eligible compared to White participants $(\mathrm{OR}=1.45,95 \%$ CI 1.03, 2.05). No significant differences in second prescriptions by race were observed (Table 4 ).
In unadjusted logistic regression models, sexual identity was also significantly associated with eligibility and first prescription. Heterosexual participants had lower odds of being eligible $(\mathrm{OR}=0.35,95 \% \mathrm{CI} 0.27,0.33)$ and lower odds of having a first prescription $(\mathrm{OR}=0.06,95 \% \mathrm{CI} 0.05$, 0.09 ) compared to gay participants. Despite there being no difference in eligibility between bisexual and gay participants, bisexual participants had lower odds of having a first prescription than gay participants $(\mathrm{OR}=0.66,95 \% \mathrm{CI} 0.52$, 0.82 ). No significant differences in second prescription by sexual identity were observed.

In unadjusted associations, year of initial appointment was positively associated with PrEP eligibility $(\mathrm{OR}=1.12$, $95 \%$ CI $1.10,1.14)$ and with first prescription $(\mathrm{OR}=1.56$, $95 \%$ CI 1.50, 1.62). Monthly income was associated with PrEP eligibility and first prescription such that people with a monthly income of $\$ 824$ to $\$ 3,343$ had higher odds of PrEP eligibility $(\mathrm{OR}=1.57,95 \% \mathrm{CI} 1.43,1.73)$ and higher odds of first prescription $(\mathrm{OR}=1.73,95 \% \mathrm{CI} 1.50,1.99)$ relative to those who earned $\$ 823$ or less. Similarly, those with a monthly income of $\$ 3,344$ or greater had higher odds of PrEP eligibility (OR $=1.73,95 \%$ CI $1.50,2.00)$ and first prescription $(\mathrm{OR}=1.14,95 \%$ CI $1.2,1.6)$ relative to those who earned $\$ 823$ or less. Participants who preferred Spanish language at the visit had lower odds of being eligible for PrEP compared to those who did not prefer Spanish $(\mathrm{OR}=0.88$, $95 \%$ CI 0.68, 0.94). Participants attending a clinic in a location other than the North Chicago clinics had higher odds of first prescription $(\mathrm{OR}=1.40,95 \% \mathrm{CI}, 1.12,1.75)$ relative to those who attended North Chicago clinics. Unadjusted estimates are presented in Table 3. 
Table 4 Crude and adjusted odds ratios from logistic regressions predicting PrEP eligibility, initiatial prescription, and second prescription in sample of Latino Men $(n=8058)$

\begin{tabular}{|c|c|c|c|c|c|c|}
\hline \multirow[t]{2}{*}{ Variable } & \multicolumn{2}{|c|}{ PrEP eligibility $(\mathrm{n}=8271)$} & \multicolumn{2}{|c|}{ First prescription $(\mathrm{n}=4335)$} & \multicolumn{2}{|c|}{ Second prescription $(n=1373)$} \\
\hline & OR $(95 \% \mathrm{CI})$ & $\mathrm{aOR}(95 \% \mathrm{CI})$ & OR $(95 \% \mathrm{CI})$ & aOR (95\% CI) & OR (95\% CI) & aOR (95\% CI) \\
\hline \multicolumn{7}{|l|}{ Race } \\
\hline White & Ref & Ref & Ref & Ref & Ref & Ref \\
\hline Latino only & $\begin{array}{r}0.60(0.55 \\
0.66)^{* * *}\end{array}$ & $\begin{array}{r}0.70(0.63 \\
0.77)^{* * *}\end{array}$ & $\begin{array}{r}0.58(0.50 \\
0.66)^{* * * *}\end{array}$ & $\begin{array}{r}0.53(0.45 \\
0.63)^{* * *}\end{array}$ & $0.8(0.7,1.1)$ & $0.82(0.65,1.04)$ \\
\hline Black & $0.86(0.68,1.09)$ & $0.90(0.70,1.16)$ & $0.73(0.53,1.03)$ & $0.79(0.52,1.21)$ & $1.0(0.5,1.7)$ & $1.10(0.61,1.97)$ \\
\hline $\begin{array}{l}\text { American Indian/ } \\
\text { Indigenous }\end{array}$ & $1.11(0.78,1.58)$ & $0.99(0.70,1.43)$ & $0.87(0.55,1.39)$ & $0.61(0.36,1.06)$ & $0.6(0.3,1.2)$ & $0.62(0.28,1.36)$ \\
\hline $\begin{array}{l}\text { Asian or Pacific } \\
\text { Islander }\end{array}$ & $0.86(0.65,1.16)$ & $0.82(0.60,1.16)$ & $1.13(0.76,1.68)$ & $0.87(0.55,1.39)$ & $0.7(0.4,1.4)$ & $0.72(0.39,1.36)$ \\
\hline Multiracial & $1.45(1.03,2.05)^{*}$ & $1.25(0.87,1.78)$ & $1.02(0.68,1.54)$ & $1.15(0.71,1.86)$ & $0.7(0.4,1.4)$ & $0.83(0.43,1.62)$ \\
\hline \multicolumn{7}{|l|}{ Sexual identity } \\
\hline Gay & Ref & Ref & Ref & Ref & Ref & Ref \\
\hline Bisexual & $1.00(0.85,1.19)$ & $0.98(0.82,1.17)$ & $\begin{array}{r}0.66(0.52 \\
0.82)^{* * *}\end{array}$ & $\begin{array}{r}0.53(0.41 \\
0.67)^{* * *}\end{array}$ & $0.75(0.51,1.09)$ & $0.76(0.52,1.11)$ \\
\hline $\begin{array}{l}\text { Heterosexual/ } \\
\text { straight }\end{array}$ & $\begin{array}{r}0.35(0.32 \\
0.38)^{* * *}\end{array}$ & $\begin{array}{r}0.30(0.27 \\
0.33)^{* * *}\end{array}$ & $\begin{array}{r}0.06(0.0,5 \\
0.09)^{* * *}\end{array}$ & $\begin{array}{r}0.04(0.03 \\
0.05)^{* * *}\end{array}$ & $0.55(0.27,1.10)$ & $0.53(0.26,1.08)$ \\
\hline Age & $\begin{array}{r}0.97(0.96 \\
0.97)^{* * *}\end{array}$ & $\begin{array}{r}0.97(0.96 \\
0.97)^{* * *}\end{array}$ & $0.99(0.98,1.00)^{* *}$ & $1.00(0.99,1.01)$ & $1.02(1.01,1.03)^{* *}$ & $1.02(1.00,1.03)^{*}$ \\
\hline $\begin{array}{l}\text { Spanish language } \\
\text { preferred }\end{array}$ & $0.80(0.68,0.94)^{* *}$ & $0.95(0.80,1.12)$ & $1.15(0.91,1.46)$ & $1.13(0.85,1.50)$ & $1.37(0.93,2.03)$ & $1.41(0.94,2.12)$ \\
\hline $\begin{array}{l}\text { Year of initial } \\
\text { appointment }\end{array}$ & $\begin{array}{l}1.12(1.10 \\
1.14)^{* * *}\end{array}$ & $\begin{array}{l}1.12(1.10 \\
1.14)^{* * * *}\end{array}$ & $\begin{array}{r}1.56(1.50 \\
1.62)^{* * *}\end{array}$ & $\begin{array}{r}1.77(1.67 \\
1.85)^{* * *}\end{array}$ & $1.02(0.95,1.10)$ & $1.06(0.98,1.14)$ \\
\hline \multicolumn{7}{|l|}{ Primary location } \\
\hline $\begin{array}{l}\text { North Chicago } \\
\text { clinics }\end{array}$ & Ref & Ref & Ref & Ref & Ref & Ref \\
\hline Other & $0.88(0.76,1.02)$ & $0.86(0.73,1.02)$ & $1.40(1.12,1.75)^{* *}$ & $1.36(1.04,1.78)^{*}$ & $0.89(0.63,1.26)$ & $0.87(0.61,1.24)$ \\
\hline \multicolumn{7}{|l|}{ Monthly income } \\
\hline$\$ 823$ or less & Ref & Ref & Ref & Ref & Ref & Ref \\
\hline$\$ 824$ to $\$ 3343$ & $\begin{array}{r}1.57(1.43 \\
1.73)^{* * *}\end{array}$ & $\begin{array}{r}1.36(1.23 \\
1.51)^{* * *}\end{array}$ & $\begin{array}{r}1.73(1.50 \\
2.00)^{* * * *}\end{array}$ & $\begin{array}{r}1.63(1.38 \\
1.94)^{* * *}\end{array}$ & $1.21(0.95,1.53)$ & $1.21(0.95,1.54)$ \\
\hline$\$ 3344+$ & $\begin{array}{r}1.73(1.50 \\
1.99)^{* * *}\end{array}$ & $1.4(1.21,1.64)^{* * *}$ & $\begin{array}{l}2.62(2.26 \\
3.14)^{* * *}\end{array}$ & $2.0(1.59,2.51)^{* * *}$ & $1.27(0.95,1.70)$ & $1.18(0.88,1.59)$ \\
\hline
\end{tabular}

\section{Multivariable Models}

In adjusted logistic models, Latino-only participants had lower odds of being eligible for PrEP (adjusted OR $[\mathrm{aOR}]=0.70,95 \%$ CI $0.63,0.77)$ and lower odds of first prescription compared to White participants $(\mathrm{aOR}=0.53$, 95\% CI 0.45, 0.63). Heterosexual participants had lower odds of PrEP eligibility ( $\mathrm{aOR}=0.30,95 \%$ CI $0.27,0.33$ ) and lower odds of first prescription compared to gay participants ( $\mathrm{aOR}=0.04,0.03,0.05$ ). Bisexual participants had lower odds of having a first prescription than gay participants ( $\mathrm{aOR}=0.53,95 \% \mathrm{CI} 0.41,0.67)$. No significant differences were observed in second prescription by race or sexual identity. Multivariable logistic regressions are presented in Table 3.

A sensitivity analysis was conducted to examine differences in models predicting first prescription. In these analyses the timeframe from the initial appointment was adjusted from one year to 6-months and 3-months thresholds. In these adjusted models, the effects of Latino-only identity and heterosexual identity on first prescription remain significant and maintain a similar effect size at the 6-month and 3-month thresholds. Although the effect size of bisexual identity remains similar, the aOR becomes marginally significant in the 6-month model $(\mathrm{aOR}=0.69$ 
$95 \%$ CI $0.45,1.06, p=0.09)$ and non-significant in the 3 -month model $(\mathrm{aOR}=0.80,95 \%$ CI $0.53,1.20, \mathrm{p}=0.28)$.

\section{Discussion}

This analysis builds on previous research that has suggested that Latino men are less likely to uptake PrEP and more likely to discontinue PrEP $[11,13]$. It speaks to heterogeneity among Latino men and highlights the importance of examining race and sexual identity when considering PrEPrelated outcomes in this population. More specifically, this analysis shows that certain subgroups of Latino men have lower PrEP eligibility (Latino-only relative to White participants, and heterosexual relative to gay participants), as well as lower PrEP initiation (Latino-only relative to White participants, bisexual relative to gay participants, and heterosexual relative to gay participants).

\section{Differences by Race}

In this analysis, we found significant differences between the Latino-only category and the White category among Latino men such that those participants who identified as Latino-only were less likely to be eligible for PrEP. Moreover, among all PrEP-eligible participants Latino-only participants were less likely to have a first prescription for PrEP despite their eligibility status. This second finding highlights lost opportunity for HIV prevention among eligible patients. While previous literature has highlighted that Latino MSM are less likely to uptake PrEP when treated as a homogenous category [11, 13], the current findings highlight the importance of considering possible within-group differences among Latino men. As currently defined, eligibility for PrEP is largely based on sexual risk profiles and shared injection equipment [32], which means one must consider how the risk profiles of Latino-only men may differ from their White-Latino counterparts when considering differences in eligibility.

Existing literature highlights unique experiences of Latino MSM tied to both their racial and sexual identities such as internalized sexual identity stigma and culturallyspecific gender norms. Research is mixed on whether Latino men may be less likely to disclose same-sex sexual behavior to healthcare providers [39]; however, some studies suggest that Latino men may be less likely to disclose same-sex sexual behaviors than white men [40]. One possible influence is traditional interpretations of masculinity that are often referred to as "machismo." Machismo and related internalized sexual identity stigma have been linked to reduced sexual identity disclosure among Latino MSM [41]. These traditional masculine norms have also been directly linked to HIV prevention behaviors among Latino MSM such as a lower likelihood of HIV testing [42] as well as lower PrEP awareness, willingness, and adherence [43]. Moreover, Latino MSM also contend with multiple forms of stigma (e.g., related to race, sexual identity, and PrEP use) as well as medical mistrust and discomfort with provider interactions, all of which may contribute to lower odds of PrEP use [44]. Additional research suggests that recent immigration status is also associated with a lower likelihood to disclose relative to individuals born in the U.S. [45, 46]. To our knowledge, it is unknown how comfort with disclosure may vary across racial identities within Latinx communities; however, it is possible that Latinx-only individuals may be less likely to disclose sexual identity or same-sex sexual behavior. Other factors may also be at play in this population such as immigration status, or a stronger identification with culturally-specific traditional gender norms relative to other racial groups within the Latinx diaspora. In regard to PrEP uptake, future analyses may want to consider assessing how the Latinx-only category may differ from other racial categories in regard to access-related variables (e.g., immigration status, insurance status), PrEP-related stigma, as well as variables related to HIV risk and risk-perception. This may also include perceptions of providers as well as targeted messaging. Indeed, in qualitative analyses, Latino MSM expressed the need for culturally appropriate messaging for PrEP advertisements [42]. Future analyses should examine ways to reach all racial subgroups within Latinx populations through appropriate messaging.

\section{Differences by Sexual Identity}

This analysis observed differences in eligibility for PrEP between heterosexual and gay men such that heterosexual men were less likely to be eligible. This finding should be understood within the context of CDC PrEP eligibility criteria that are largely risk-based with an emphasis on condomless anal sex between cisgender men [47]. That being said, this analysis suggested that the most frequently used eligibility criteria among heterosexual men were multiple partners and previous STI history, with no heterosexual men meeting the eligibility criteria of condomless sex (vaginal or anal). Indeed, existing literature suggests that heterosexual MSM are less likely to disclose same-sex sexual behavior to medical doctors compared to gay men [45, 48], which may suggest that these particular risk measures are underreported in these populations. At the same time, heterosexual men were much less frequently deemed eligible without a specific criterion relative to gay and bisexual men. Some research suggests that heterosexual people vulnerable to HIV are among the least likely to be prescribed PrEP by healthcare providers [49], though it should be noted that this prior research did not disaggregate MSM by sexual identity (e.g. bisexual, gay). Assumptions of relative importance of PrEP 
prescription by sexual identity may be in part why providers are less likely to assign PrEP eligibility to a heterosexual man without a specific recorded reason, and more likely to deem gay men as eligible without recording a specific reason. Another plausible explanation is that gay men may be more likely to initiate conversations about PrEP with providers as compared to bisexual or heterosexual men.

Even among those who were eligible based on the CDC criteria, heterosexual men were less likely to have a first prescription relative to gay men. This difference represents a lost opportunity to prevent potential HIV transmission in these patients. There is a dearth of research on PrEP in heterosexual men in the context of the United States. Heterosexual men are among the least likely populations to be presented to healthcare providers as potential PrEP candidates in PrEP-related training curriculum across all regions of the U.S. [50]. This trend may impact the degree to which healthcare providers perceive heterosexual men as candidates for PrEP despite there being PrEP eligibility criteria that are relevant to heterosexual men (e.g. having a partner living with HIV, being diagnosed with an STI, having condomless sex, sharing needles, and participating in sex work). While heterosexual men may be less likely to acquire HIV more broadly, heterosexual men who are at risk of HIV transmission should be taken seriously as PrEP candidates. Some of the aforementioned psycho-social variables may also be at play among heterosexual Latino men who are eligible for PrEP, such as intersecting forms of stigma (HIV stigma, sexual identity stigma, and racism) as well as adherence to culturally-specific traditional gender norms. Few studies of heterosexual men examine PrEP outcomes across the PrEP continuum or using longitudinal data [51]. More research is needed to understand why PrEP-eligible heterosexual Latino men are less likely to initiate a PrEP regimen. Researchers may also need to examine targeted communication strategies for PrEP-eligible heterosexual men [52].

By contrast, a difference in eligibility was not observed between bisexual and gay men. Gay and bisexual men in this analysis shared the same top 5 eligibility criteria, though bisexual men appeared to have higher frequency of participation in exchange sex in this sample. Yet, bisexual men were less likely to have a first prescription for PrEP as compared to gay men at the one year threshold. This finding is similar to previous literature that suggests that bisexual men are less likely to use PrEP than gay men despite having a unique risk profile (e.g., more likely to use substances before sex, more likely to engage in insertive condomless sex with a casual male partner) [27]. These findings are troubling in that, on average, bisexual men were not less eligible for PrEP than gay men, but were still less likely to get an initial PrEP prescription. It should be noted that this effect became marginally significant when the threshold for initial PrEP prescription was adjusted to 6 months and non-significant when it was adjusted to 3 months in sensitivity analyses, which raises questions about potential explanations. Possible speculative explanations may include time-varying characteristics like partner gender in that bisexual men who partner with women after having previously being screened eligible for PrEP may experience a waning perceived importance of PrEP. Bisexual men may also experience a higher degree of fluctuation in healthcare access overtime, as some research suggests that bisexual populations experience a greater degree of unemployment and uninsured status relative to their heterosexual and gay peers [53].

The reason for lower initial prescription among bisexual participants can't be readily discerned from the present data, but a difference in PrEP prescription between bisexual and gay men could represent barriers at the provider or patient level. There are a number of possible factors contributing to potential barriers at the provider level. While one study examined representations of sexual identity in clinician training on PrEP, bisexuality was subsumed under a broader MSM category [50]. It is possible that the unique behavioral or clinical presentations of bisexual individuals are incorporated in clinician training. Moreover, there are currently no evidence-based HIV prevention interventions that are tailored to bisexual men [54] and that existing interventions focus on anal sex with male partners which may alienate bisexual men who have female and non-binary partners [55]. There is also a need for bisexual-affirming messaging in PrEP campaigns to better reach bisexual men who may not see themselves reflected in advertisements that are depicting gay men or same-sex male relationships [20]. While there are possible factors at play among providers, bisexual men may also face a range of unique obstacles to PrEP care such as unique forms of stigma, lower perceived HIV risk, lower perceived need for PrEP or barriers to access.

In addition to previously mentioned culturally-specific gender norms, intersectional stigma, and internalized identity stigma, Latino Bisexual men experience unique forms of stigma [20] such as experiencing bisexual stigma among heterosexual and gay communities. Stigma in intimate relationships with women may also be at play such that female partners may stigmatize bisexual men's identity which could feasibly contribute to hesitancy to use PrEP, especially if PrEP seen as a medication linked to same-sex attraction. This may be exacerbated by the fact that daily oral forms of PrEP can be difficult to conceal in certain contexts, particularly if a couple is cohabitating. Bisexual populations may also have reduced access to healthcare overall, and a higher likelihood to delay healthcare visits [56] and face lower rates of insurance access relative to gay patients [57]. Bisexual men are also less likely to disclose same-sex sexual behavior to medical doctors compared to gay men [45, 48], so same-sex sexual risk indicators may be under reported 
among bisexual men, which may impact eligibility assessments and communication about PrEP.

Taken together, these findings emphasize the heterogeneity in Latino men by racial identity and sexual identity and emphasize the need for research to further understand differences in PrEP outcomes across these identities. Furthermore, efforts should be made to ensure that procedures following the identification of PrEP-eligible patients encourage equitable uptake of PrEP across sexual identity and race. Additional efforts or messaging may be necessary to ensure that Latino-only patients, heterosexual patients, and bisexual patients receive adequate information about PrEP.

\section{Limitations}

This study has notable strengths, including the use of a large sample from electronic medical records, therefore representing the reporting of real-world results. Moreover, by employing the "Bi Us, For Us" model [33] and partnering with bisexual health advocates and a large healthcare network, the findings were immediately delivered to community partners allowing for immediate impact. Some limitations should be noted. The sample was confined to one health system in Chicago, limiting generalizability. As this dataset is from an EMR, results reflect actual clinical practices, which speaks to the study's ability to present clinical reality. Use of EMR can reduce some biases found in survey research such as recall bias, social desirability bias, and Hawthorne Effects (i.e. changes in behaviors due to a participants' knowledge of being studied) [58]. That being said, EMR like all forms of data presents its own biases. For example, EMR data has less precise/uniform protocols for data collection. Clinical practices often allow for individual clinical judgement in addition to standard screening procedures. This means that there may have been bias introduced into the data based on individual medical providers' clinical judgements. Providers may also have varying approaches to data collection with less regulation than in a controlled research environment. Data in EMR includes predominantly healthcare seeking individuals, which may miss healthier or medicine-adverse individuals. This analysis focused on initial appointments where patients were screened for PrEP eligibility. Future analyses should include longitudinal analytic techniques including assessment of PrEP eligibility at multiple time points. Much of the PrEP research examines PrEP use through self-report and some survey research differentiates stages of PrEP use (e.g. initiation, adherence, discontinuation). In the present study using electronic medical records we were only able to examine PrEP prescriptions, but were not able to examine prescription fills or use of the prescribed pills. Reasons for not pursing a second prescription were not collected in the EMR data, so we were unable to discern reasons that participants did not purse their second prescription. Moreover, we set up time frames between identification of PrEP eligibility and first prescription as well as between first prescription and second prescription. These were based on the average time to PrEP initiation from the literature [36, 37] and based on the number of pills prescribed relative to the days between prescriptions. Additionally, some relevant variables were not available in the current dataset such as immigration status or family's national origins. These additional variables would be informative, especially for characterizing the Latino-only category.

\section{Conclusion}

The full diversity of Latinx populations should be considered when crafting HIV prevention strategies including the delivery of PrEP. In particular, differences by sexual identity and racial identity should be addressed. Future mixed-methods analyses should examine racial categories within Latinx populations such as examining how individuals who identify exclusively as Latinx perceive PrEP and healthcare interactions related to PrEP. Further research should examine why bisexual men who are equivalently eligible for PrEP as their gay counterparts are not initiating PrEP regimens.

Acknowledgements Brian Feinstein's time was supported by a grant from the National Institute on Drug Abuse (K08DA045575). This project was supported by the Third Coast Center for AIDS Research's Ending the HIV Epidemic (EHE) Project Planning Grant awarded to PI Dr. Richard D'Aquila and Project Directors Lauren Beach and Laura Rusie (5P30AI117943-05 REVISED). The content is solely the responsibility of the authors and does not necessarily represent the official views of the funding agency.

\section{Declarations}

Conflict of interest All authors declare that they have no conflict of interest.

\section{References}

1. Centers for Disease Control and Prevention. Basic statistics 2021 [Available from: https://www.cdc.gov/hiv/basics/statistics.html.

2. Centers for Disease Control and Prevention. HIV and Gay and Bisexual Men 2021 [Available from: https://www.cdc.gov/hiv/ group/msm/index.html.

3. Centers for Disease Control and Prevention. HIV and African American Gay and Bisexual Men 2021 [Available from: https:// www.cdc.gov/hiv/group/msm/bmsm.html.

4. Centers for Disease Control and Prevention. HIV and Hispanic/ Latino Gay and Bisexual Men 2021 [Available from: https://www. cdc.gov/hiv/group/msm/hispanic-latino.html.

5. Koechlin FM, Fonner VA, Dalglish SL, O'Reilly KR, Baggaley $\mathrm{R}$, Grant RM, et al. Values and preferences on the use of oral pre-exposure prophylaxis (PrEP) for HIV prevention among 
multiple populations: a systematic review of the literature. AIDS Behav. 2017;21(5):1325-35.

6. Eaton LA, Driffin DD, Bauermeister J, Smith H, ConwayWashington C. Minimal awareness and stalled uptake of preexposure prophylaxis (PrEP) among at risk, HIV-negative, black men who have sex with men. AIDS Patient Care STDS. 2015;29(8):423-9.

7. Grant RM, Anderson PL, McMahan V, Liu A, Amico KR, Mehrotra M, et al. Uptake of pre-exposure prophylaxis, sexual practices, and HIV incidence in men and transgender women who have sex with men: a cohort study. Lancet Infect Dis. 2014;14(9):820-9.

8. Marshall BD, Mimiaga MJ. Uptake and effectiveness of PrEP for transgender women. The lancet HIV. 2015;2(12):e502.

9. Wilson EC, Jin H, Liu A, Raymond HF. Knowledge, indications and willingness to take pre-exposure prophylaxis among transwomen in San Francisco, 2013. PLoS ONE. 2015;10(6):e0128971.

10. Mayer KH, Chan PA, Patel R, Flash CA, Krakower DS. Evolving models and ongoing challenges for HIV pre-exposure prophylaxis implementation in the United States. J Acquired Imm Deficiency Synd (1999). 2018;77(2):119.

11. Control CfD, Prevention, editors. HIV prevention pill not reaching most Americans who could benefit-especially people of color. Conference on Retroviruses and Opportunistic Infections, Boston, MA: National Center for HIV/AIDS, Viral Hepatitis, STD, and TB Prevention Newsroom; 2018.

12. Birkett M, Neray B, Janulis P, Phillips G, Mustanski B. Intersectional identities and HIV: race and ethnicity drive patterns of sexual mixing. AIDS Behav. 2019;23(6):1452-9.

13. Cuevas AG, Dawson BA, Williams DR. Race and skin color in Latino health: An analytic review. Am J Public Health. 2016;106(12):2131-6.

14. Sheehan DM, Trepka MJ, Fennie KP, Prado G, Cano MÁ, Maddox LM. Black-white latino racial disparities in HIV survival, Florida, 2000-2011. Int J Environ Res Public Health. 2016;13(1):9.

15. Feldman MB. A critical literature review to identify possible causes of higher rates of HIV infection among young black and Latino men who have sex with men. J Natl Med Assoc. 2010;102(12):1206-21.

16. Bean FD, Tienda M. The hispanic population of the United States: Russell Sage Foundation; 1988.

17. Telles E. Latinos, race, and the US Census. Ann Am Acad Pol Soc Sci. 2018;677(1):153-64.

18. Cornell S, Hartmann D (2006) Ethnicity and race: Making identities in a changing world: Sage Publications

19. Hitlin S, Brown JS, Elder GH Jr. Measuring Latinos: Racial vs ethnic classification and self-understandings. Soc Forces. 2007;86(2):587-611.

20. Feinstein BA, Dodge B. Meeting the sexual health needs of bisexual men in the age of biomedical HIV prevention: Gaps and priorities. Arch Sex Behav. 2020;49(1):217-32.

21. Everett BG. Sexual orientation disparities in sexually transmitted infections: examining the intersection between sexual identity and sexual behavior. Arch Sex Behav. 2013;42(2):225-36.

22. Bauer GR, Brennan DJ. The problem with 'behavioral bisexuality': Assessing sexual orientation in survey research. Journal of Bisexuality. 2013;13(2):148-65.

23. Young RM, Meyer IH. The trouble with "MSM" and "WSW": Erasure of the sexual-minority person in public health discourse. Am J Public Health. 2005;95(7):1144-9.

24. Caceres BA, Brody AA, Halkitis PN, Dorsen C, Yu G, Chyun DA. Sexual orientation differences in modifiable risk factors for cardiovascular disease and cardiovascular disease diagnoses in men. LGBT health. 2018;5(5):284-94.

25. Jeffries WL IV. HIV testing among bisexual men in the United States. AIDS Educ Prev. 2010;22(4):356-70.
26. Agronick G, O'donnell L, Stueve A, San Doval A, Duran R, Vargo S. Sexual behaviors and risks among bisexually-and gayidentified young Latino men. AIDS Behav. 2004;8(2):185-97.

27. Feinstein BA, Moran KO, Newcomb ME, Mustanski B. Differences in HIV risk behaviors between self-identified gay and bisexual young men who are HIV-negative. Arch Sex Behav. 2019;48(1):261-75.

28. Jin F, Prestage G, Law M, Kippax S, Van de Ven P, Rawsthorne $\mathrm{P}$, et al. Predictors of recent HIV testing in homosexual men in Australia. HIV Med. 2002;3(4):271-6.

29. Holloway IW, Dougherty R, Gildner J, Beougher SC, Pulsipher C, Montoya JA, et al. Brief report: PrEP uptake, adherence, and discontinuation among california ymsm using geosocial networking applications. J Acquir Immune Defic Syndr. 2017;74(1):15-20.

30. Parsons JT, Rendina HJ, Lassiter JM, Whitfield TH, Starks TJ, Grov C. Uptake of HIV pre-exposure prophylaxis (PrEP) in a national cohort of gay and bisexual men in the United States. J Acquir Immune Defic Syndr. 2017;74(3):285-92.

31. Grov C, Rendina HJ, Jimenez R, Parsons JT. Using online settings to identify gay and bisexual men willing to take or with experience taking PrEP: Implications for researchers and providers. AIDS Educ Prev. 2016;28(5):378-92.

32. Owens DK, Davidson KW, Krist AH, Barry MJ, Cabana M, Caughey AB, et al. Preexposure prophylaxis for the prevention of HIV infection: US Preventive Services Task Force recommendation statement. JAMA. 2019;321(22):2203-13.

33. Baeten JM, Donnell D, Ndase P, Mugo NR, Campbell JD, Wangisi $\mathrm{J}$, et al. Antiretroviral prophylaxis for HIV prevention in heterosexual men and women. N Engl J Med. 2012;367(5):399-410.

34. services Cntswn. 6 months of COVID-19: timeline of the outbreak and how politics, sports, entertainment and the economy changed. Chicago News Tribune. 2020.

35. Beach LB, Xavier Hall CD. Bi Us, For Us: Articulating foundational principles for research in partnership with bisexual communities. J Bisexuality. 2020;2020:1-22.

36. Rolle C-P, Rosenberg ES, Siegler AJ, Sanchez TH, Luisi N, Weiss $\mathrm{K}$, et al. Challenges in translating PrEP interest into uptake in an observational study of young black MSM. J Acquired Imm Deficiency Synd (1999). 2017;76(3):250.

37. Serota DP, Rosenberg ES, Sullivan PS, Thorne AL, Rolle C-PM, Del Rio C, et al. Pre-exposure prophylaxis uptake and discontinuation among young black men who have sex with men in Atlanta, Georgia: a prospective cohort study. Clin Infect Dis. 2020;71(3):574-82.

38. Mansergh G, Herbst JH, Holman J, Mimiaga MJ. Association of HIV pre-exposure prophylaxis awareness, preferred Spanish (vs. English) language use, and sociodemographic variables among Hispanic/Latino men who have sex with men. Ann Epidemiol. 2019;31:8-10.

39. Qiao S, Zhou G, Li X. Disclosure of same-sex behaviors to health-care providers and uptake of HIV testing for men who have sex with men: a systematic review. Am J Mens Health. 2018;12(5):1197-214.

40. Wall KM, Khosropour CM, Sullivan PS. Offering of HIV screening to men who have sex with men by their health care providers and associated factors. J Int Assoc Physicians AIDS Care. 2010;9(5):284-8.

41. Munoz M, D’Aniello C. Latinx LGBQ young adults' comingout experiences. The American Journal of Family Therapy. 2020;48(2):160-76.

42. Horridge DN, Oh TS, Alonzo J, Mann-Jackson L, Tanner AE, Song EY, et al. Barriers to HIV testing within a sample of spanishspeaking latinx gay, bisexual, and other men who have sex with men: implications for hiv prevention and care. Health Behavior Res. 2019. https://doi.org/10.4148/2572-1836.1069. 
43. Rivera DB, Brady JP, Blashill AJ. Traditional Machismo, Caballerismo, and the pre-exposure prophylaxis (PreP) cascade among a sample of Latino sexual minority men. J Sex Res. 2021;58(1):21-8.

44. Rosengren-Hovee AL, Lelutiu-Weinberger C, Woodhouse EW, Sandanapitchai P, Hightow-Weidman LB. A scoping review of HIV pre-exposure prophylaxis stigma and implications for stigmareduction interventions for men and transwomen who have sex with men. AIDS Behav. 2021;25:2054-70.

45. Bernstein KT, Liu K-L, Begier EM, Koblin B, Karpati A, Murrill C. Same-sex attraction disclosure to health care providers among New York City men who have sex with men: implications for HIV testing approaches. Arch Intern Med. 2008;168(13):1458-64.

46. Oster AM, Russell K, Wiegand RE, Valverde E, Forrest DW, Cribbin M, et al. HIV infection and testing among Latino men who have sex with men in the United States: the role of location of birth and other social determinants. PLoS ONE. 2013;8(9):e73779.

47. Smith DK, Koenig LJ, Martin M, Mansergh G, Heneine W, Ethridge SF, et al. Preexposure prophylaxis for the prevention of HIV infection-2014: clinical providers' supplement. 2014.

48. Ng BE, Moore D, Michelow W, Hogg R, Gustafson R, Robert W, et al. Relationship between disclosure of same-sex sexual activity to providers, HIV diagnosis and sexual health services for men who have sex with men in Vancouver. Canada Canadian J Public Health. 2014;105(3):e186-91.

49. Adams LM, Balderson BH. HIV providers' likelihood to prescribe pre-exposure prophylaxis (PrEP) for HIV prevention differs by patient type: a short report. AIDS Care. 2016;28(9):1154-8.

50. Bunting SR, Garber SS, Goldstein RH, Ritchie TD, Batteson TJ, Keyes TJ. Student Education About Pre-exposure Prophylaxis (PrEP) Varies Between Regions of the United States. JGIM: Journal of General Internal Medicine. 2020;35(10).

51. Roth AM, Tran N, Felsher M, Szep Z, Krakower D. Heterosexual men anticipate risk compensatory behaviors with future preexposure prophylaxis initiation: findings from an exploratory crosssectional study. Sex Transm Dis. 2019;46(10):e97-100.
52. Sophus AI, Mitchell JW. A review of approaches used to increase awareness of pre-exposure prophylaxis (PrEP) in the United States. AIDS Behav. 2019;23(7):1749-70.

53. Charlton BM, Gordon AR, Reisner SL, Sarda V, Samnaliev M, Austin SB. Sexual orientation-related disparities in employment, health insurance, healthcare access and health-related quality of life: a cohort study of US male and female adolescents and young adults. BMJ Open. 2018;8(6):e020418.

54. Hergenrather KC, Emmanuel D, Durant S, Rhodes SD. Enhancing HIV prevention among young men who have sex with men: A systematic review of HIV behavioral interventions for young gay and bisexual men. AIDS Educ Prev. 2016;28(3):252-71.

55. Dodge B, Van Der Pol B, Reece M, Malebranche D, Martinez O, Goncalves G, et al. Rectal self-sampling in non-clinical venues for detection of sexually transmissible infections among behaviourally bisexual men. Sexual Health. 2012;9(2):190-1.

56. Wolstein J, Charles SA, Babey SH, Diamant AL. Disparities in Health Care Access and Health Among Lesbians, Gay Men, and Bisexuals in California. Policy Brief (UCLA Center for Health Policy Research). 2018;2018(9):1-8.

57. Ward BW, Dahlhamer JM, Galinsky AM, Joestl SS. Sexual orientation and health among US adults: National Health Interview Survey, 2013. 2014.

58. Casey JA, Schwartz BS, Stewart WF, Adler NE. Using electronic health records for population health research: a review of methods and applications. Annu Rev Public Health. 2016;37:61-81.

59. Vidal-Ortiz S, Martínez J. Latinx thoughts: Latinidad with an X. Lat Stud. 2018;16(3):384-95.

60. Torres L. Latinx? Lat Stud. 2018;16:283-5. https://doi.org/10. 1057/s41276-018-0142-y.

Publisher's Note Springer Nature remains neutral with regard to jurisdictional claims in published maps and institutional affiliations. 